\section{ECONOMICS}

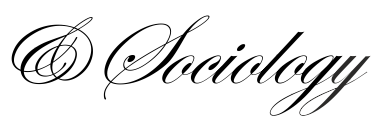

Danaj, A., Lazányi, K., \& Bilan, Y. (2018). Perceptions and Implications of Immigration in France - Economic, Social, Political and Cultural Perspectives. Economics and Sociology, 11(3), 226-247. doi:10.14254/2071-789X.2018/11-3/14

\title{
PERCEPTIONS AND IMPLICATIONS OF IMMIGRATION IN FRANCE - ECONOMIC, SOCIAL, POLITICAL AND CULTURAL PERSPECTIVES
}

\author{
Adela Danaj, \\ Doctoral School for Safety Sciences, \\ Obuda University, \\ Hungary \\ Email:adela.danaj@uet.edu.al \\ Kornélia Lazányi, \\ Keleti Faculty of Business and \\ Mangement, Obuda University, \\ Hungary \\ Email:lazanyi.kornelia@kgk.uni- \\ obuda.hu \\ Yuriy Bilan, \\ Faculty of Management \\ Rzeszow University of Technology, \\ Poland, \\ Email:yuriy_bilan@yahoo.co.uk
}

\author{
Received: December, 2017 \\ 1st Revision: July, 2018 \\ Accepted: October, 2018
}

DOI: $10.14254 / 2071-$

789X.2018/11-3/14

\begin{abstract}
Europe is facing a new challenge - namely that of migration, and the negative attitudes stemming from the constant inflow of immigrants. Although France has historic experience with social inclusion and immigration issues, even there, the 2014 regional elections indicated mistrust towards immigrants. Present paper endeavors to analyze the phenomenon from economic, social, political and cultural perspectives based on the data provided by the European Social Survey focusing on the case of France. Research results indicated that trust is an important factor when it comes to attitudes towards immigrants. On the one hand, those, who have lower level of trust in national institutions, such as the police are more afraid of immigrants and of the threats they might pose. On the other hand, mistrust rooted in dissimilarity - like difference in religions - is also significant based on the data displayed in the article.
\end{abstract}

JEL Classification: F22, O15 Keywords: immigration, trust, social involvement, France

\section{Introduction}

In the recent years, Europe has faced several new waves of massive immigration. The increase of migratory inflow over time has become a challenge for all European countries. Thus, many societies all over Western Europe have reinforced their negative attitudes towards immigrants. Thereupon, this study attempts to identify the main determinants behind this phenomenon.

This project focuses on the French case, since sociodemographic pressure and tense political debates over the questions of identity and integration of immigrants are more and more explicit in French society. The 2014 regional elections in France showed that 6.8 million French casted their votes for Front National - a far right party. The campaign of Marine Le Pen - the 
leader of this party, was mostly based on anti-immigration rhetoric's. Therefore, it is evident that immigration has become a source of concern for policy makers and the public in general. As the 2017 Presidential elections are coming closer, we believe that these dynamics make France a very interesting case, which is also empirically relevant for measuring French people's attitudes towards immigrants.

The overall goal of this project is to develop a social discourse on the attitudes towards immigrants and immigration in general, by raising awareness on how the perceptions towards immigrants affect their inclusion into French society. Five dimensions that will be explored are as follows. The first part explores the sociodemographic determinants of the French people's perceptions about the economic benefits of migrants. The second addresses the relationship between trust in political institutions and the acceptance of immigrants. The third part looks into the relationship between national security perceptions and the acceptance of immigrants. The fourth part highlights the cultural inclinations towards perceptions of immigrants. The last part focuses on the impact of religious values on the perception of migrants.

In order to fulfill the project's objectives, multivariate statistical analysis was conducted and each of the aforementioned dimensions was addressed as an individual research. The dataset used for this project was provided by the 2014 edition of the European Social Survey (ESS 7).

\section{Part A. The impact of education, income, employment and parent's origins on French citizens' perception of the economic benefits of migrants}

\section{Introduction and Theoretical Framework}

Public debate over immigration in France has been for many years a product of consensus between parties from left to right, on the basic values of the labor market and right of asylum. However, the global economic changes and the shift from a heavy industry toward a sector requiring skilled service increased unemployment for unskilled workers during the nineties (Madrak-Grochowska, 2015; Jantoń-Drozdowska \& Majewska, 2015; Mačerinskienė \& Aleknavičiūtè, 2017; Rollnik-Sadowska \& Dąbrowska, 2018). Recently, the deep economic recession of 2008 hit society and the perception of effectiveness of social justice, particularly hard in all Europe. French unemployment reached 3.3. millions people in 2014. These factors, among others, are related to the competition between native's French workers and the immigrant competition. This conflict has been exploited by anti-immigration parties and poses a challenge to policy making.

Economist of migration explains this social division with the changes in the labor market which is created by migration. Some scholars have theorized that, assuming elasticity of capital supply, the way immigration impact outcomes depend on the skill structure of immigrants relatively to the skill structure of natives (Dustmann et al., 2008; Kotulič \& Adamišin, 2012; Strielkowski, \& Weyskrabova, 2014). Borjas (2003), argues that similar educated workers with difference level of experience participating in the labor market are not perfect substitutes. Both of these approaches show that immigration lowers the wages of competing workers (Holicza \& Stone, 2016 Vasile \& Androniceanu, 2018, Tvaronavičienè, 2018). However, both studies have been conducted using data from United State. Therefore, I argue, those theories might not fit the European context, since in Europe the labor mobility is a marginal factor. A more pertinent study for our scope, which focus on Europe, argues the economic and wage convergence between sending and receiving country was a feature of the initial wave of migration (Barslund et al., 2014; Jędrzejowska-Schiffauer \& Schiffauer, 2017; Mikalauskiene et al., 2017), which has been undermined by the 2008 economic crisis. Assuming that migration has an impact on the labor market, appropriate and rational policy of integration might help to overcome the 
conflict between native's French workers and the immigrant competition. Migration show also to have large impact on the child domestic labor on the market and woman employment (as head of the family) as in the study (Bilgen-Susanli et. al., 2017).However, those policies should focus on the understanding of the social dynamics and perception of the migration phenomena. Immigration has a large impact on the crime rate (Lobont et al., 2017).

However, those policies should focus on the understanding of the social dynamics and perception of the migration phenomena.

Therefore, the purpose of this study is to estimate the impact of of socio- economic determinants on the perception of French citizens of the economic benefit of migrants. My results suggest that low education level, low income and unemployment, as well as parental origins, have an impacts on perception of citizens on the economic benefit of migrants.

\section{Hypothesis}

My aim is to generalize the relationship between education level, income level, unemployment and parent's origins and negative perception of migrants in the economic dimension. My hypothesis is that low income, unemployed and low level of education determine a negative perception of the economic value of migrants.

\section{Data}

To estimate the impact of socio- economic determinants on the perception of French citizens of the economic benefit of migrants, national survey data from the seventh round of the European Social Survey (ESS 7) will used. The European Social Survey is a biannual social survey of population aged 15 years and over, designed to chart and explain the interaction between European's changing institutions and the attitude, belief and behavior of the populations. Downloaded on February 28, 2016, the original database contains information's from responded in France, fielded between 31 October 2014 and 13 March 2015.

\section{Measurements}

\subsection{Response Variable}

In order to estimate the perception of French citizens of the economic benefit of migrants, the attitudinal indicator $\operatorname{IMBECO}(\mathbf{E})$ will be used as response variable. The wording of the survey question is "Would you say it generally bad or good for France' economy that people come to live here from other countries?". The original categorical variable has ten level of measurement (Bad for economy - 1-2- 3-4-5-6-7-8-9-Good for economy). For the purpose of the study, the categorical variable has been recoded and collapsed as dichotomous one: categories $0-4$ takes the value of 0 , labelled Bad for the economy, while 5 to 10 , takes the values of 1 , labelled Good for the economy.

\subsection{Explanatory Variables}

In order to estimate the of socio -economic determinants on the perception of French citizens of the economic benefit of migrants, this study will use as explanatory variables of interests the follow indicators: Unemployment (U), doing last 7 days: unemployed, actively looking for job (Levels: Marked, Not Marked), Income (I), household's total net income, all sources (Levels: From 1st decile to 10thdecile), Education (Y), years of education full time 
completed (Levels: continuous). Since I am looking to the perception of French citizens, to control that the respondents were not immigrants, the control variable Mother origins $(\mathbf{M})$, mother born in country (Levels: Yes/No) and Father origins $(\mathbf{F})$, father born in country (Levels: Yes/No) will be used. The variable Income has been recoded into Very Low Income/ Low Income/ Medium Income/ High Income, while the variables Education in Low Level / Medium Level /High Level, according with the French educational system.

It is my belief that the decision made in recoding the variables represent a viable compromise for efficiency of the analysis. The number of observations $(\mathrm{N}=1917)$, after accounting for the missing values, is satisfactory for run the model.

\section{Methodology}

Due to the nature of my variables, I will employ Log - linear analysis, since it works well for categorical response and explanatory variables with more than two categories. The log - linear analysis involves modelling the relationship between the variables, and it is appropriate for the scope of this study, since it will allow me to look at meaningful interaction effects.

The log - linear analysis employs a model, which includes five of the variables discussed above. The observations were obtained using a random sampling frame. All variables are normally distributed. Even though the categories were merged, there were not enough observations in each cell in the frequencies table. To overcome the violation of this assumption, I decide to conduct three separate log-linear analyses holding the variables Mother Origins and Father Origins, and progressively substitute the variables Education, Income and Unemployment.

For each analysis, I verified the optimal model fit by running multiple feasible models. I obtained a considerable number of models with a significant $\mathrm{p}$ - values for each analysis. However, the model with the highest $p$ - values were too complex for the scope of my research and the interaction effects did not meaningfully contribute to my research question. Thus, I decided to choose the most parsimonious models, based on the simplicity criteria, which allows less interaction. The model that has been chosen (Table 1) for each analysis is the one where all the explanatory variables have a direct effect on the response variable, and there are not interaction effects.

Table 1. Model

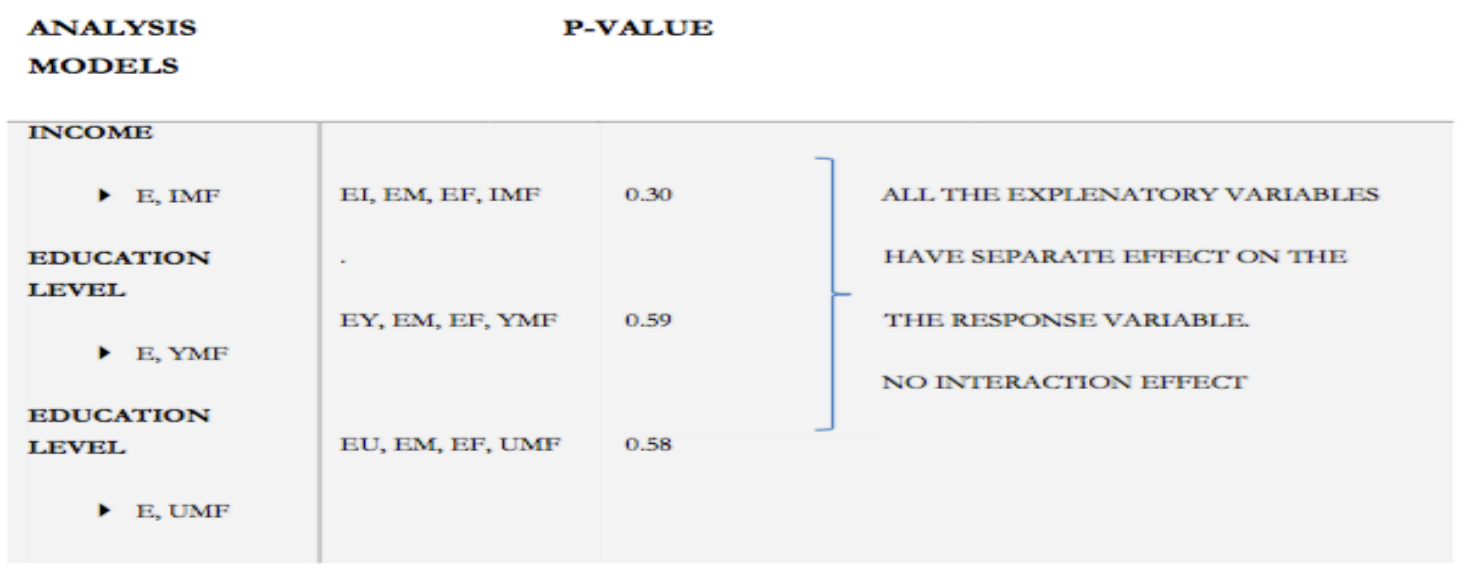

Source: own compilation 


\section{Results}

\subsection{Multiplicative parameters of the log - linear analysis: Income Level}

The odds ratio of the multiplicative parameters (Table 1.1) show that people with very low income are 6.18 times more likely to believe that migrants worsen the national economy, compared with people with high income level. People with low income are, furthermore, 4.8 times more likely to believe that migrants are a threat for a national economy, compared with high income people. The results show also that there is not a substantive difference comparing medium income level with high income level (0.58).

Table 1.1 Odds Ratios

Income Level

\begin{tabular}{llll}
\hline & $\begin{array}{l}\text { VERY LOW } \\
\text { INCOME/HIGH INCOME }\end{array}$ & $\begin{array}{l}\text { LOW INCOME/HIGH } \\
\text { INCOME }\end{array}$ & $\begin{array}{l}\text { MEDIUM INCOME } \\
\text { /LOW INCOME }\end{array}$ \\
\hline WORSE & 6.18 & 4.8 & 0.58 \\
\hline BETTER & 0.16 & 0.20 & 1.75
\end{tabular}

Source: own compilation

According to my findings, it seems that French citizens with mother born in country are 2.56 times more likely to perceive migrants as a threat to national economy (Table 1.2), compared with people with mother born outside the country.

Table 1.2. Odds Ratio

\begin{tabular}{lll}
$\begin{array}{l}\text { Mother Origins } \\
\text { Father Origins }\end{array}$ & \\
\hline & MOTHER BORN IN COUNTRY/OUT & FATHER BORN IN COUNTRY/ OUT \\
\hline WORSE & 2.56 & 1.03 \\
BETTER & 0.38 & 0.97
\end{tabular}

Source: own compilation

Interestingly, people with father born in country are about as likely to perceive migrants as a threat for national economy compared with people with father born in country. As showed in table 2.2 and 3 , these results do not change significantly with changing other control variables: Income, Unemployment and Education.

Substantially, I have reasons to believe that citizens with mother born in country are more likely to believe that migrants are a threat for the national economy. However, a possible explanation it could be justified by the fact that French males are more likely to have children with migrants, while female tends to have children with native French, suggesting that a mother marrying a foreigner is particularly open minded. This might be investigating by further research. 


\subsection{Multiplicative parameters of the log - linear analysis: Level of Education}

The results show that education is even more important than income level for determining negative perception of migration. People with low educational level are 12.5 times more likely to perceive migrants as a threat for national economy, compared with people with high level of education (Table 2.1). People with medium educational level, so people with bachelor degree, are 4.42 times more likely to perceive migrants as threat for the national economy, compared with people with high level of education. Moreover, there is not a substantive difference between people with medium level of education and low education. People with medium level of education are just about half as likely to perceive migrants as threat for the economy.

Table 2.1 Odds Ratio

\begin{tabular}{cccc} 
Level of Education & & & \\
\hline & $\begin{array}{c}\text { LOW EDUCATION } \\
\text { LEVEL/HIGH }\end{array}$ & MEDIUM/LOW & MEDIUM/HIGH \\
\hline WORSE & 12.5 & 0.45 & 4.42 \\
\hline BETTER & 0.07 & 2.86 & 0.22
\end{tabular}

Table 2. 2 Odds ratio
\begin{tabular}{llr} 
Mother Origins \\
Father Origins & MOTHER BORN IN COUNTRY/OUT & FATHER BORN IN COUNTRY/ OUT \\
\hline WORSE & 2.56 & 1.03 \\
\hline BETTER & 0.38 & 0.97
\end{tabular}

Source: own compilation

\subsection{Multiplicative parameters of the log - linear analysis: Unemployment}

Unemployed People are 1.30 times more likely to perceive migrants as a threat for national economy, compared with employed people (Table 3).

Table 3. Odds Ratio

Employment

Mother Origins

Father Origins

\begin{tabular}{cccc}
\hline & UNEMPLOYED/EMPLOYED & $\begin{array}{c}\text { MOTHER BORN IN } \\
\text { COUNTRY/OUT }\end{array}$ & $\begin{array}{c}\text { FATHER BORN IN } \\
\text { COUNTRY/ OUT } \\
\text { WORSE }\end{array}$ \\
BETTER & 1.30 & 2.61 & 0.94 \\
\hline
\end{tabular}

Source: own compilation 


\section{Conclusions and Limitation}

The substantive findings of this research give me reasons to believe that socio demographic determinants have an impact on the perception of economic dimension of migration. This finding is in line with my hypotheses. Nevertheless, I find the effect of unemployment lower than expected. An unexpected finding is that French people with mother born in country tent to have a negative perception of migrants, while origin of father seems not to have a substantial impact.

These results can be explained through supply/ demand in the labor market. Low income people might perceive migrants as competition increasing the supply of low skilled labor, which pushes down low skilled wages. Meanwhile, high income people might perceive migrants as beneficial because of the decrease of prices for services produced by low skilled workers. This theory confirms my hypothesis and seems to confirm the theory of Borjas. Due to the effects of the 2008 economic crisis in Europe and evidence of previous income convergence, the point made by Barslund et al. still remains valid.

Nevertheless, one limitation of my study should be considered. The attitudinal indicator of the responsible variable used in the study is too general. The wording of the survey question: "Would you say it generally bad or good for France' economy that people come to live here from other countries?" doesn't make a distinction between high skilled and low skilled migrants. It would be interesting to repeat the study with a more specific attitudinal indicator.

\section{Part B. Institutional Trust and the attitude toward Migration and Immigrants-The case of France}

\section{Overview}

Trust is an interpersonal phenomenon. A willingness to take risk and act in the light of the anticipated behavior of the other party (Hardin, 2002). However, trust cannot only be defined on a personal level, but has implications on wider scales - such as organizational or national level - as well (Uslaner, 2008). Fukuyama (1995) even defined trust as the building block of societies. In a way, trust is the basis for social ties and social capital. Since trust is inevitable in uncertain situations, where risk is an inherent variable, people tend to trust those like them more, than those completely different from them (Birds of a feather flock together). Approaching the same phenomenon from a different point of view, mistrust is more prevalent in relations, where the parties are rather different in any features, let it be external, like hair or skin color, or internal, such as religion, or the basic value set or assumptions (Newton, 2001). Some aspects of this phenomenon can be observed in a multinational student environment when there are unforeseen distress, broken relationships and trust, vulnerability and conflicts in universities (Petersons \& Khalimzoda, 2016).

Among the European countries population is easy to identify negative images and perceptions towards immigrants. At the same time these negative perceptions are showed in several empirical evidence confirming deliberate prejudice against them. These negative perceptions signal mistrust (Newton, Zmerli, 2011). Thus, immigration is transformed in a noticeable issue and it is considered as problematic by most of developed countries citizens. Many of these countries have seen the rise of anti-immigrant sentiments related with the economic, cultural, political and legal context. Since this part of the study will be focused only at the political dimension, it will take a political-psychological analytical perspective (Green and Seher, 2003) to understand the negative attitudes toward immigrants in French.

It is important to note that the effectiveness of political institutions is a relevant factor when studying the political state. Thus, in this research will be examined an institutional puzzle 
and institutionalism theories seems to be the most obvious starting point. These theories claim that institutions matter because they "exert patterned higher-order effects on the actions, indeed the constitution of individuals and organizations without requiring repeated collective mobilization or authoritative intervention to achieve these regularities" (Jepperson, 1991, p. 145).

\subsection{Research Focus and Objectives}

This study aims to find out the relationship existing between perceptions toward immigrants and satisfaction with the recent state economy, trust in the national parliament and trust in the legal system; secondly provide a theoretical background for each of the variables, lastly the main objective of this article, is to analyze the prominence of the hypothesis and conclude whether this hypothesis stands for French case.

\section{Literature Review}

This section of the article reviews the theoretical background of the relationship between perceptions towards immigrants among French citizens, satisfaction with the economy state, trust in National Parliament and trust in the Legal System (Solomon, Flores, 2001). Further this section states the academic discussion regarding their relationship and after completing the theoretical frame, it ends up with the hypothesis development.

The wider theoretical and empirical suggestions of the study operate to the areas of citizens' prejudice and citizens' relations also. Several scholars relate the citizens' prejudice to cultural marginality theory, human capital theory, political affiliation, societal integration, and neighborhood safety (Rustenbach, 2000). It was found in various literatures a huge interest in public views toward immigrants and a comparatively diminished focus on reactions to immigration (Meuleman et al., 2009). However, comparing the conceptual framework of people attitudes toward immigrants by the prejudice literature has not brought any substantive finding, thus "original questionnaire items tap into very different stories such as perceptions about the consequences of immigration for the receiving societies" can raise up new approaches about the issue (Ceobanu \& Escandell, 2010). According to Societal attachment theory the antiimmigrants' attitude is associated in several ways. Nevertheless, it is accepted that people with low interpersonal trust tends to be distrustful among ethnically diverse communities. At the other hand, higher trust relates to not blaming immigrants unless one has had a personal negative experience with them (Hooghe et al., 2006). Consequently, trust has a direct effect towards (anti) immigrants' attitude. In this study, Societal attachment is measured through interpersonal trust of French citizens, thus in the individual level. In order to provide a large variety of institutions, it was decided to include in the study institutions that represented the legislative-national parliament, executive-current state economy and juridical-legal system.

\subsection{Hypothesis Development}

This research is leaded by the RQ: How does the satisfaction within the state, political and legal institutions effect the perception towards immigrants?

In order to respond to the research question stated above, this study hypothesizes that:

During the new wave of massive immigrations, French citizens with low interpersonal trust tend to be more distrustful towards immigrants.

Based on the literature above, a non-rejected hypothesis is expected. 


\section{Variables, Data and Methodology}

This section provides evidence about the data collection and methodology used to generate the empirical findings. The timeframe where the analysis is based relates with the 2014 European Social Survey editions. The sample covers 1805 observations.

\subsection{Data Design}

The main variables where the analysis is based are (i) Trust in National Parliament; (ii) Trust with Legal system; (iii) Satisfaction with the current state economy; (iv) Immigrants make country worse or better place.

The explanatory variables are as below: Trust in National Parliament and Legal trust relate to perceptions of the degree of trust as seen by citizens, and ranges between 1 (low trust), 2 (indifferent) and 3 (high trust). The same range was used for "satisfaction with the current state economy": 1 (low satisfaction), 2 (indifferent) and 3 (high satisfaction). Regarding the response variable, Immigrants make country worse or better place, it relates to perceptions of the degree of acceptance by French citizens and ranges between 0 (worst) 1 (better).

All the variables mentioned above are collapsed into dichotomous and discrete since they were continuous and were measured on an 11-point scale. The response variable is collapsed in dichotomies, meanwhile the Explanatory variables into discrete with three categories. It is interesting to understand how the neutral stance of citizens reacts towards immigrants, thus was decided not to exclude respondents with such a position. Consequently, the three explanatory variables were collapsed in three categories.

\subsection{Methodology}

In order to identify the relationship between French citizen towards immigrants and their determinants, a log-linear model is applied; where Migration "worst-better place" is considered to be the response variable, while the Satisfaction with present state of economy in country, Trust in country's parliament and Trust in the legal system are the explanatory variables.

\subsection{Findings and Analysis of Results}

This section provides the main findings; it presents several models, which fulfill the two requirements: better fit and simplicity. Once, were run a number of potential log linear models and were testing ( 0.05 threshold of model fit for testing conditional independence) all possible models, it was found that there are three models, which satisfied all the requirements.

Since all the three models present a good model fit, it was decided to choose the simpler model, thus the model 3. This model shows that trust in the national parliament, in the Legal system and the satisfaction with the current state economy, each have separate effects on the respondents' attitudes towards immigration. These separate effects are presented at the following tables.

According to the relationship between Satisfaction with present state of economy in country and attitudes towards immigration, the odds ratios suggest that citizens who are not satisfied with the economy in the country are 2.19 times more likely than those who are satisfied, to believe that immigrants make the country worse place, in comparison to those who believe they make it better place. Meanwhile, respondents who have a neutral state regarding the economy are 1.16 times more likely than those who are satisfied, to believe that immigrants make the country worse place, in comparison to those who believe they make it better place. 
Table 1. Model

\begin{tabular}{|l|l|l|}
\hline \hline Model & $\begin{array}{l}\text { p-value } \\
\text { (model fit) }\end{array}$ & Explanation \\
\hline \hline Model 2 & 0.59 & $\begin{array}{l}\text { Trust in legal system has a separate effect on attituted towards } \\
\text { immigrantts, meanwhile satisfaction with current economy and } \\
\text { trust in the National Parliament have both separate and joint } \\
\text { effects on attitudes towards immigration. With a high p-value, } \\
\text { we don't see enough evidence to reject this model. However, } \\
\text { the model is complex too. }\end{array}$ \\
\hline$((1,4),(1,2,3),(2,3,4))$ & $\begin{array}{l}\text { This model allows for individual effects } \\
\text { Satisfaction with the current state's economy, Trust in the } \\
\text { national parliament and trust in legal system, all have separate } \\
\text { effects on attitudes towards immigration. }\end{array}$ \\
\hline $\begin{array}{l}\text { Model 3 } \\
((1,2),(1,3),(1,4),(2,3,4))\end{array}$ & 0.51 & \\
\hline \hline
\end{tabular}

Source: Autbor

** $1=$ immigrant worst vs. better place; $2=$ satisfaction with economy; $3=$ trust in parliament; $4=$ trust in legal system

Table 2. Perceptions vs. Satisfaction with the current state economy

\begin{tabular}{|l|r|r|r|}
\hline \hline Odds Ratio & \multicolumn{3}{|c|}{ Satisfaction with present state of economy in country } \\
\hline \hline & Low/Indifferent & Indifferent/High & Low/High \\
\hline \hline $\begin{array}{l}\text { Negative } \\
\text { Perceptions }\end{array}$ & 1.88 & 1.16 & 2.19 \\
\hline \hline $\begin{array}{l}\text { Positive } \\
\text { Perceptions }\end{array}$ & 0.52 & 0.86 & 0.45 \\
\hline
\end{tabular}

\section{Source: own compilation}

Thus, it can be concluded that the trend shows that those with low level of satisfaction compared with respondents who showed high level of satisfaction within the state economy, are more than two times more likely to have negative behavior towards immigrants than respondents with high trust.

Odds Ratio presented at table 4, show that people who have shown low trust in the National Parliament seems to be 2.02 times more likely than those who have high trust to have negative sentiments towards immigrants. When looking at the relationship between trust in the national parliament and attitudes towards immigration, the odds ratios suggest that respondents with neutral trust seems to be 1.1 times more likely than people with high trust in parliament to have negative sentiments towards immigrants. In this case also, was found that people who show low trust tend to be almost two times more likely to have negative perceptions towards immigrants than respondents with high trust.

Table 3. Perception vs. Trust in country's parliament

\begin{tabular}{|l|r|r|r|}
\hline \hline Odds Ratio & \multicolumn{4}{|l|}{ Trust in country's parliament } \\
\hline \hline & Low/Indifferent & Indifferent/High & Low/High \\
\hline \hline $\begin{array}{l}\text { Negative } \\
\text { Perceptions }\end{array}$ & 1.83 & 1.10 & 2.02 \\
\hline \hline $\begin{array}{l}\text { Positive } \\
\text { Perceptions }\end{array}$ & 0.55 & 0.9 & $\bullet$ \\
\hline \hline
\end{tabular}

Source: own compilation 
According to table 5, people who have shown low trust in the Legal System seems to be 2.28 times more likely than those who have shown high trust to have negative sentiments towards immigrants. Meanwhile, when looking at the relationship between legal system and attitudes towards immigrants, the odds ratio suggests that respondents with neutral trust seems to be 1.09 times more likely than people with high trust in parliament to have negative sentiments towards immigrants. It is interesting to understand how is it possible that almost the same result as others above, are shown. In this case also, people who had shown low trust tend to be almost two times more likely to have negative perceptions towards immigrants than respondents with high trust.

Table 4. Perception vs Trust in Legal system

\begin{tabular}{|l|r|r|r|}
\hline $\begin{array}{l}\text { Odds } \\
\text { Ratio }\end{array}$ & \multicolumn{3}{|l|}{ Trust in legal system } \\
\hline \hline & Low/Indifferent & Indifferent/High & Low/High \\
\hline \hline $\begin{array}{l}\text { Negative } \\
\text { Perceptions }\end{array}$ & 2.08 & 1.09 & 2.28 \\
\hline \hline $\begin{array}{l}\text { Positive } \\
\text { Perceptions }\end{array}$ & 0.47 & 0.91 & 0.43 \\
\hline \hline
\end{tabular}

Source: own compilation

\section{Concluding Remarks}

To sum up, the findings identified that low trust in the institutions examined in the framework of the study, define negative behavior towards immigrants. It was surprise to find that all the explanatory variables such as: satisfaction with the current state economy, trust in national parliaments and trust in legal system demonstrated that are almost equaled significant. It has to be underlined that due to practical issues this study was not developed deeper in order to better understand the phenomenon. However, it can be considered as a good start for further studies in the field. To conclude, it was found that the hypothesis presented was confirmed. Thus, satisfaction with the current state economy and trust in institutions transforms into some more negative attitudes towards immigrants.

\section{Limitations of the Study}

Despite the significant findings, this study has some limitations, related to the limitations of using a log-linear model. Once, it was decided to use this model all the variables were collapsed into dichotomous and discrete categories. Due to this step, categories face the risk to lose significant information. Nevertheless, this model was appropriate due to the big number of the observations.

\section{Part C. Immigration attitudes, religion and cultural diversity: An exploratory analysis}

\section{Introduction}

France, being a historically characteristic example of the 'ethos of secularization', also with its diverse ethnic composition and multicultural values, is an interesting, perhaps atypical 
case regarding the applicability of various findings on how different levels of religiosity of native citizens and their cultural attitudes might influence their immigration-attitudes.

To look at the relationship of these attitudes for the specific French case, I have formulated the following research question: How do the religious characteristics of the respondents and their attitudes towards cultural diversity influence their position on immigration inflow; furthermore, how are these attitudes affected by immigrants' religious background?

\section{Theoretical background}

Religious and cultural attitudes have been popularly discussed topics amongst scholars focusing on social perception of immigration, for which the European Social Survey data has provided rich comparative potential across European countries, as the following examples show.

Healy \& Breen (2014) have analysed changes in religiosity and religious practice as influenced by the 2008 economic crisis by using European Social Survey data between 2002 and 2012 in three austerity countries with Catholicism being their main religion (Ireland, Spain, Portugal). They tested the existential security theory to explain religious change in societies undergoing dramatic social change. According to their findings, religion, religious faith and religiosity are complex phenomena, which, although to some extent increase in case of perceived and existential insecurity, change slowly and gradually with secularization of modern states and are determined by the given country's historical, political and sociocultural particularities.

Regarding the intra-national dimension of religious differences, as Aleksynska \& Chiswick's findings (2011) in their Europe-wide analysis of differences between immigrants and native born citizens in religiosity implied, immigrants tended to be more religious compared to native born citizens, regardless of their religious denomination, although religiosity of immigrants generally declines with the years since migration, suggesting a certain adaptation to the destination country's life (due to church attendance's role as also an essential response to the need to establish new networks and mitigate loneliness, as well as to capitalize on originspecific human capital).

A case study of Greece on religion, securitization and anti-immigration attitudes based on ESS data (Karyotis \& Patrikios, 2010), attempted to explore the dynamics of competition and relative discursive power of political and religious elites regarding public immigration attitudes. In their findings they demonstrated that if citizens are exposed to securitizing religious discourse through church attendance, they are immunized from the 'softening effect of the political message', which provides explanation for the survival of the migration-themed security frame in Greece, regardless of political attempts to de-securitize this frame. In this sense, religious elites can be significant stakeholders in securitization of immigration-attitudes, through melding national and religious identity, where the church's defence of faith is equated with that of national identity. Overall, these findings suggested that religiosity is amongst the strongest predictors of anti- immigration attitudes in Greece.

As a study with different emphasis, Boomgaarden \& Freire (2009), were focusing on religiosity's effects on Euroscepticism, by using immigration attitudes as mediator. Partial results have shown that anti-immigration attitudes (besides authoritarianism) are somewhat influenced by respondents' religious denomination and level of religiosity, and also predict Euroscepticism (though only indirectly) - however, the given country's general religious context seems to be more important than individual religiosity. Contrarily to findings of Karyotis \& Patrikios (2010), religiosity was found to depress anti-immigration attitudes in general (thus, indirectly fostering support for European integration). 
Another research supports the conclusions of Karyotis \& Patrikios (2010): Ivarsflaten's (2005) research on 18 Western European countries' ESS data has strongly supported her hypothesis regarding national identity concerns that emerged as a result of worries about diminished national unity and uniqueness. These concerns have increased popular demand for restrictive immigration and asylum policies due to the fear that religious, linguistic and cultural

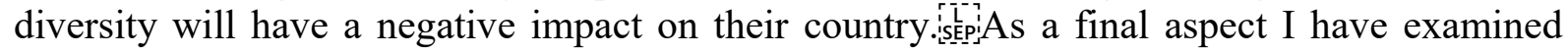
regarding the relationship of religious-cultural-immigration attitudes, the work of Green (2007) on developing the typology of different 'gatekeeping attitudes' through cross-national comparison was of central importance when designing my research.

These attitudes refer to three main criteria: blatant and subtle forms of xenophobia, the level of endorsement of different admission standards for immigrants who want to enter European states, and the expulsion criteria for immigrants transgressing norms and laws. By performing cluster analysis on national majority members' scores of endorsement on individual (e.g., language \& working skills) and categorical (e.g., skin colour, religion) entry criteria and individual expulsion criteria (e.g., criminal act, long-term unemployment), she has created a typology of three constitutive elements: strict gatekeepers scored high on all criteria, lenient gatekeepers opposed all of them, while individualist gatekeepers favoured the individual and opposed categorical criteria (e.g., skin colour, religion), the latter one implying a somewhat intermediate position between distinguishably anti- and pro-immigrant positions - however, it shares characteristics of both other groups: they oppose categorical criteria, but support individual ones (this was the most characteristic for French ESS respondents of the three categories) - still, it is inconclusive whether this position implies simple adherence to antiblatant norm thus concealing xenophobic categorical attitudes or whether people of this position genuinely support a meritocratic immigration policy.

Based on these contradictory findings of the current extant literature, I have decided to conduct an exploratory study; therefore, I haven't used predetermined hypotheses. This way I could examine whether there are more-or-less independent attitudes there are in case of the chosen closely related attitude-items and what their content is.

\section{Data}

The data I have analysed is derived from the European Social Survey's (ESS) 7th wave that was conducted in 2014. The biennial measure which is built around two rotating thematic modules is a comparative attitude and behavioural survey that consists of a comprehensive base module, several standardized demographic variables and questions regarding central attitude, behavioural and value questions. It is considered as one of the most widely accepted standardised cross- country comparative project since 2002, including individual data from more than 30 countries overall (Berg \& Hjerm, 2010). In this paper I will use the sample collected in France, 2014. The original sample size of this individually collected data is 1917 , which was designed to be representative of the population above the age of 15 and was selected with random probability. that were also related to cultural and religious attitudes. In the thus remaining data I had the responses of 1779 participants on 8 continuous variables. These were the following:

- imueclt: Country's cultural life undermined or enriched by immigrants (measured on an 11-point scale: 0-10; regarded as continuous, also in case of similarly scaled items)

- imwbcnt: Immigrants make country worse or better place to live (scale: $0-10$ )

- rlgueim: Religious beliefs and practices undermined or enriched by immigrants (scale:

- aljewlv: Allow many or few Jewish people to come and live in the country (4-point scal e: 1-4; for comparability in regressions \& ANOVAs: regarded as continuous) 
- almuslv: Allow many or few Muslims to com and live in the country (scale: 1-4)

- qfimchr: Qualification for immigration: Christian background (11-point scale: 0-10)

- qfimwht: Qualification for immigration: be white (scale: 0-11)

- qfimlng: Qualification for immigration: speak country's official language (scale: 0-11)

The last five items had to be reversed in order to achieve similarly structured scales, where the lo west scores imply most anti-immigrant attitudes and the highest ones correspond to more positive opinion scores.

\section{Analysis \& Results}

I have chosen Exploratory Factor Analysis to examine the possibly existing, more-orless independent attitudes, which were later turned to 'super variables'.

To determine the number of factors that could be meaningfully extracted from the data set, I have chosen the method of Parallel Analysis which compares the eigen values of the data to those of a same-sizerandomdataset.Basedontheseresults,Idecidedtotestforatrifactorialstructure which accounted for $54 \%$ of the cumulative variance in the data. The hypothesis test for that three factors are sufficient for the data provided confirming results: The Chi Square test ( 10.18 wit $\mathrm{h} \mathrm{df}=7$ ) with $\mathrm{p}=.179$ was higher than .05 , therefore, I have decided to adhere to a tri factorial structure to analyse the data.

A bi-factorial structure would have only explained $43 \%$ of the cumulative variance (with $\mathrm{p}<.05$ ), while using four factors would have increased this valuw to $59 \%$ (with p-value <.05). The decision to keep three factors was also supported by the Parallel Analusis Scree Plot with two distinguishable break points.

After determining the number of factors, I have performed Exploratory Factor Analysis with Varimax-rotation. Based on the previously determined trifactorial structure, I have used a threshold of .5 to exclude all factor components that didn't load distinguishably on any of the three factors, that have explained $54 \%$ of the variance in the data.

The contents of the resulting three factors were the following: Muslims \& Jews not to be allowed/ to be allowed to enter; country's cultural \& religious life and life in general made worse/better by immigrants; matters/ doesn't matter for qualification of accepting immigrants: Christianity \& whiteness of immigrants.

Factor 1 have shown that immigration-attitudes are somewhat similarly structured and evaluated in case of referring to cultural (loading on Factor 1: 0.83 ), religious $(0.51)$ and general (0.76) influences of immigration inflow on the receiving country.

Apparently, items inquiring about allowing Muslims and Jews to the country are similarly evaluated by the respondents. However, the item referring to Muslims loaded higher on the factor (0.92, compared to loadings for the other item: 0.69), therefore it is more characteristic of it (Factor 2).

Factor 3 includes items referring to the qualification of accepting immigrants. As the two items in the factor have shown, the Christianity and whiteness of the immigrants are similarly evaluated. This follows an intuitive expectation that these attributes constitute the basic dimension of distinction between "us" (native citizens) and "them" (immigrants).

According to the histograms and skewness scores, only Factor 1 (skewness of -0.238593 ) has shown almost perfectly normal distributions. However, in case of Factor 2 $(-0.505062)$ and Factor $3(-0.1611405)$, the lack of such apparent normality vastly decreases the robustness of my related findings and further analyses, therefore I have decided to only examine Factor 1.

Afterwards, Factor 1 was analyzed with OLS regression run for all resulting continuous response variables (i.e., the content of the factor: because the contained items were measured on the same scale, I have added the corresponding 3 variables without further computations) 
with all explanatory variables ('agea': age, 'rlgdgr': religiosity, 'rlgatnd_reversed': frequency of attendance of religious services, 'pplstrd': worse/ better for a country if everyone shares customs), in each case. However, the R-squared values were too low for interpretable results, therefore I have decided to keep only the discrete explanatory variables (age, religiosity, frequency of attendance of religious services, worse/ better for a country if everyone shares customs) and run multiway analyses of variance for the (also discrete) factor (as dependent variable) in order to obtain more meaningful and interpretable results than those of the OLS regression's.

To check the homogeneity of variance, Levene's test was performed on Factor 1. As $\mathrm{p}=0.00000032$ with $\mathrm{F}=5.0141$ and $\mathrm{df}=10$, the test was statistically significant, therefore the assumption has not been violated.

To check the homogeneity of variance, Levene's test was performed on Factor 1. As $\mathrm{p}=0.00000032$ with $\mathrm{F}=5.0141$ and $\mathrm{df}=10$, the test was statistically significant, therefore the assumption has not been violated. The results of the multiway analysis of variance, with a chosen alpha-level of .05, are shown in Table 1

Table 1. Results of multiway ANOVA

\begin{tabular}{|l|l|l|l|l|}
\hline Variable & Sum of Squares & Df & F-value & P-value \\
\hline rlgdgr & 1 & 33 & 1.231 & 0.267 \\
\hline rlgatnd_reversed & 1 & 0 & 0.015 & 0.903 \\
\hline Pplstrd & 1 & 15277 & 562.221 & 0.000 \\
\hline agea & 1 & 417 & 15.356 & 0.000 \\
\hline rlgdgr:pplstrd & 1 & 71 & 2.625 & 0.105 \\
\hline Residuals & 1819 & 27 & & \\
\hline
\end{tabular}

\section{Source: own compilation}

The results were insignificant for 'rlgdgr' ('How religious are you) at a $\mathrm{p}=0.267$ with $\mathrm{F}=1231 \& \mathrm{df}=33$, therefore we cannot reject the corresponding null hypothesis that the different extents of religiosity don't make a difference in how people think in terms of immigration attitudes. Similarly, we could also not reject the null hypothesis for 'rlgatnd_reversed' ("How often attend religious services apart from special occasions), due to the insignificance of this variable's individual effect at $\mathrm{p}=0.903$, with $\mathrm{F}=0.015 \& \mathrm{df}=0$.

However, 'pplstrd' ("Better for a country if almost everyone shares customs and traditions"; at $\mathrm{p}<0.0000000000000002$ with $\mathrm{F}=562.221 \& \mathrm{df}=15277$ ) and 'agea' (age, at $\mathrm{p}=0.0000923$ with $\mathrm{F}=15.356 \& \mathrm{df}=417$ ) were statistically significant, therefore we could reject the respective null- hypotheses that age and attitude towards cultural homogeneity don't have effects on the means of the immigration-attitudes (measured as Factor 1). Furthermore, I observed an insignificant interaction effect of religiosity and cultural homogeneity-attitude (at $\mathrm{p}=0.105$ with $\mathrm{F}=2.625 \& \mathrm{df}=71$ ), which was the only relevant interaction effect I wanted to examine, based on the theoretical background - in conclusion, there was no observable interaction effect of these two key variables.

Overall, my results don't provide substantial support for any of the previous findings, nor do they confirm that the level of religiosity influences immigration-related attitudes. 
However, there seems to be a statistically significant relationship between the immigrationattitudes and attitudes towards cultural homogeneity.

\section{Limitations and future research}

In my analysis I have used secondary survey data, therefore the measures for some of the relevant attitudes were not ideal (e.g., using only two items to measure religiosity, without distinguishing between different denominations, thus I couldn't measure cross-religious differences in immigration attitudes). Furthermore, I had to arbitrarily generalize 4-point scales as discrete for the comparability of variables in my Factor Analysis.

An additional limitation is a consequence of the length of the European Social Survey. The chosen items' evaluation could also have been influenced by the closer context of questions before them. Throughout filling such an extensive survey, with time, the respondents' attention and motivation could also decrease to rigorously consider their answers. Due to fading attention and motivation, the results on similarly structured items may not imply real differences, as some are probably not distinguished in detail in such a lengthy survey-filling setting.

A crucial limitation already holds the opportunity for future research. As the most recent available data from the ESS was collected in 2014, the intensified European immigration inflow, the rise of the anti-Muslim attitudes propagated by the populist Front National, and particularly the French terrorist attacks of 2015 couldn't yet have been accounted for. However, a cross time comparison with more recent French data could highlight the subtler mechanisms and interactions of religiosity- (both of native citizens' and immigrants'), cultural diversity- and immigration-attitudes.

\section{Part D. National security perceptions and acceptance of immigrants: The case of France}

\section{Overview}

In the past few years immigration has become a security matter of prime importance in Europe, or as Huysmans highlights "migration has been increasingly presented as a danger to the public order, cultural identity, and domestic and labor market stability"(2000, p. 752). Nevertheless, the security dilemma has instigated major disagreements among the European politicians. For instance, the French President François Hollande, while criticizing the antiimmigration discourse, said that the anti-immigration sentiments produce a "discourse of fear" and warned that "foreigners are always accused of every ill" (Hollande, 2012 in Samuel, 2014: Bobakova, 2017). By looking at President Hollande's statements, one can conclude that he is emphasizing the importance of accepting immigrants, besides the security risk that immigration has been associated with. Therefore, it is puzzling what might be the connection between these two. Given the aforementioned, the question that guides my research is the following: How do perceptions about national security affect the acceptance of immigrants in France. The theoretical explanations will be presented in the following chapter.

\section{Theoretical framework}

As mentioned before, the connection between immigration and security could be analyzed through many perspectives. The focus of this paper will be put on the nationalor internal security perspective. One of the theoretical explanations that describe the relation between immigration and national security is embodied in the concept of security continuum, which means that migration is perceived as a security threat because it is being associated with 
acts of terrorism, drugs traffic and other crimes (Huysmans, 2000). While exploring the attitudes towards immigrants in France, Simon and Sikich (2007) found out that in 2003, 44\% of the French population thought that immigrants increase crime. Thus, so as to analyze the perceptions of security of the citizens, Loader and Mulcahy (2003) suggest that one should look at the level of confidence in the police forces.

Nevertheless, given the aforementioned, the societal factors are also relevant indicators for one's perceptions about security and thus one's attitude towards the immigrants. This relation could be explained through the concept of societal security, which suggests that immigration can be perceived as a security threat that can endanger one's individual, group or national identity (Alexseev, 2006). In the case of France, the vast majority of the immigrants are of non-European origin (Pan Ké Shon and Verdugo, 2015). Thus, having in mind the assimilationist nature of the French immigration model, with regards to the superiority of the French culture and language, any refusal of some immigrants to abandon their different religious practices, such as the Muslim women's tradition of wearing a veil in a public space, is perceived as a threat (Martin, 1994), which therefore causes feelings of insecurity and unsafety among the members of the cultural majority (Florack et al., 2003). Having said the above, it seems that in the case of France religion plays an important role in shaping people's attitudes towards immigrants.

\section{Variables, missing data and methodology}

The data for France used in this paper is taken from European Social Service's website. It originates from 2014, as there was no newer data available. In order to answer the previously mentioned research question and operationalize the theoretical solutions, I used four variables: allow many/few immigrants of different racelethnic group from majority (imdeftn), trust in police (trstplc), feeling of safety walking alone in a local area after dark (aesfdrk), and religion or denomination belonging to at present (rlgdnm). The data-set had 1917 observations, with 973 missing data. This large number of missing data was due to the large number of missing values in the 'religion or denomination belonging to at present' variable. Later in this chapter, I will explain how I solved this issue. Given that all my variables, except 'trust in police', were categorical and my research question refers to a regression type problem, I use log-linear analysis as my research method. Nonetheless, so as to meet the methodological criteria I had to recode my variables. In order to conduct the analysis, I used the statistical software 'R-Studio'.

I did the recoding as follows. My response variable was consisted of four categories (1 - allow many to come and live here; 2 - allow some; 3 - allow a few; and 4 - allow none). I recoded it as a binary variable, by merging the categories 1 and 2, and 3 and 4, after which the variable has two categories ( 0 - people who would generally allow immigrants; 1 - people who generally would not allow immigrants). My first explanatory variable - allow many/few immigrants of different racelethnic group from majority was originally a continuous variable measured on an 11-point scale (0 - no trust at all; 10 - complete trust). I recoded it as a dichotomous variable, by collapsing it around the mean. After the recoding, the variable has two categories ( 0 - people who generally do not trust the police; 1 - people who generally trust the police). I used the same approach with the second explanatory variable - feeling of safety walking alone in a local area after dark. The variable was originally consisted of four categories ( 1 - very safe; 2 - safe; 3 - unsafe; and 4 - very unsafe), and I recoded it as a dichotomous variable by merging the categories 1 and 2, and 3 and 4 respectively. The recoded variable has two categories ( 0 - people who feel generally safe; 1 - people who feel generally unsafe).

The third explanatory variable - religion or denomination belonging to at present, was initially contained of eight categories (1 - Roman Catholic; 2 - Protestant; 3 - Eastern Orthodox; 4 - Other Christian denomination; 5 - Jewish; 6 - Islamic; 7 - Eastern religions; 8 
- Other non-Christian religions). However, the missing data made up 50.8\% of all the individual observations in the variable, out of which, $50.7 \%$ were coded as 'not applicable'. Given the large percent of missing data, I concluded that they should not have happened by chance. Therefore, I made a new category out of the missing data coded as 'not applicable', and named it 'Religious affiliation not indicated'. Thereafter, the missing data contained only 8.6\% (166 observations) of the whole data- set. Thus, I decided that the remaining missing data should not harm the analysis and I removed it from the data-set. Furthermore, I recoded this variable by collapsing it at three categories (1 - Major religion, 2 - Minor religions, 3 - Religious affiliation not indicated). Namely, because the respondents who affiliated with the Roman Catholic Church made up $40.1 \%$ of the total data, the respondents who claimed to belong to some of the remaining religions or denominations jointly made up $9.2 \%$ of the total data, and the respondents who did not indicate their religious affiliation consisted $50.7 \%$ of the overall data, reducing the number of categories as described above seemed the most reasonable option.

Having in mind the theoretical recommendations, I expect that the people who generally do not trust the police and those who generally feel unsafe will be less likely to accept immigrants. I expect the similar attitude towards immigrants from those people who claim to belong to the major religion.

\section{Models}

Before I proceeded with the modelling, I ran a chi-square test of independence as to check whether there is independence in the data. The chi-square test of independence, with chisquare $=110.67, \mathrm{df}=18$ and $\mathrm{p}$-value $=2.36 \mathrm{e}-15$, showed good results, given that the $\mathrm{p}$-value is much lower than 0.05 . Furthermore, when I was choosing the model, I was looking for parsimonious models with a good model fit $(\mathrm{p}>0.05)$. I started with the most complicated models and continued looking for a model that will meet the above described criteria. I came up with 5 fitting models: ${ }^{1}$

Table 1 Model fit

\begin{tabular}{lc}
\hline \multicolumn{1}{c}{ Model } & P-value \\
\hline 1: $(1,2,3),(1,2,4),(2,3,4)$ & 0.31 \\
2: $(1,2,3),(1,3,4),(2,3,4)$ & 0.85 \\
3: $(1,2,3),(1,4),(2,3,4)$ & 0.72 \\
4: $(1,2,3),(1,3),(2,3,4)$ & 0.56 \\
5: $(1,2),(1,3),(1,4),(2,3,4)$ & 0.82 \\
\hline
\end{tabular}

\section{Source: own compilation}

Out of these models, I chose Model 5, given that it is a model with a good model fit ( $\mathrm{p}$ $>0.05$ ) and it also meets the simplicity criteria. This model shows that trust in police, feeling of safety walking alone in a local area after dark, and religion or denomination belonging to

\footnotetext{
${ }^{1}$ The 'allow many/few immigrants of different race/ethnic group from majority' variable will be denoted with '1, the 'trust in police' variable will be denoted with '2', the 'feeling of safety walking alone in a local area after dark' variable will be denoted with '3', and finally, the 'religion or denomination belonging to at present' variable will be denoted with ' 4 '.
} 
at present all have separate effect on the response variable. Additionally, I believe that all of the effects are substantively significant.

\section{Findings and discussion Multiplicative parameters and effects of Model 5}

Table 2

Allow many/few immigrants of different race/ethnic group from majority

\begin{tabular}{ccc} 
Trust in police & $\begin{array}{c}\text { People who would generally } \\
\text { allow immigrants }\end{array}$ & $\begin{array}{c}\text { People who would generally not } \\
\text { allow immigrants }\end{array}$ \\
\hline $\begin{array}{c}\text { People who generally do not } \\
\text { trust the police }\end{array}$ & 0.88 & 1.13 \\
People who generally trust the & 1.13 & 0.88 \\
police & &
\end{tabular}

Source: own compilation

By looking at the results presented in Table 2, it seems that people who generally do not trust the police are 1.13 times more likely not to allow immigrants to come in France than those who generally trust the police forces.

Table 3

Allow many/few immigrants of different race/ethnic group from majority

$\begin{array}{ccc}\begin{array}{c}\text { Feeling of safety walking alone in } \begin{array}{c}\text { a local area after } \\$\cline { 2 - 2 }\end{array} \\ \text {$People who generally feel safe }\end{array} & \begin{array}{c}\text { People who would generally } \\ \text { allow immigrants }\end{array} & \begin{array}{c}\text { People who would generally not } \\ \text { allow immigrants }\end{array} \\ \text { People who generally feel unsafe } & 1.47 & 0.68 \\ \end{array}$

\section{Source: own compilation}

In line with the theoretical expectations, the findings in Table 3 show that people who generally feel unsafe are 1.47 times more likely not to accept immigrants, than those who generally feel safe.

Table 4

Religion or denomination

Major religion

Minor religions

Religious affiliation not indicated

Source: own compilation
Allow many/few immigrants of different race/ethnic group from majority

\begin{tabular}{cc}
\hline $\begin{array}{c}\text { People who would generally } \\
\text { allow immigrants }\end{array}$ & $\begin{array}{c}\text { People who would generally not } \\
\text { allow immigrants }\end{array}$ \\
0.76 & 1.31 \\
1.18 & 0.85 \\
1.11 & 0.90
\end{tabular}


Finally, Table 4 demonstrates that the people who claim adherence to the major religion, unlike those who belong to the minor religions or did not indicate their religious affiliation, are 1.31 times more likely not to welcome immigrants.

\section{Conclusion and limitations}

ON the basis of the data it seems that French citizens who perceive immigrants as a threat to the national security, that is, those who generally have lower trust in the police and those who generally feel unsafe are less likely to allow immigrants to come in France. Furthermore, people who claim to belong to the major religion would rather refuse immigrants with race and ethnicity different from the majority, which meets Alexseev and Florack et al' expectations. Nevertheless, further research may discover other factors that affect the acceptance of immigrants. For instance, one could include ethnicity, gender, age, as to test additional relations. Even though my research provided significant results, it had certain limitations. As to satisfy the methodological criteria, I had to re-code my variables as dichotomous, which may result in loosing valuable information.

\section{Acknowledgement}

Present paper has been supported through the New National Excellence Program of the Ministry of Human Capacities of Hungary.

\section{References}

Aleksynska, M., \& Chiswick, B.R. (2011). Religiosity and migration: Travel into one's self versus travel across cultures.

Alexseev, M.A. (2006). Immigration Phobia and the Security Dilemma: Russia, Europe, and the United States. Cambridge University Press.

Barslund, M., Busse, M., Vargas-Silva, C., Kaczmarczyk, P., Baas, T., Peinado, M., Jimeno, J., Lacuesta, A., Galgóczi, B., \& Leschke, J. (2014). Labour mobility in the EU: Dynamics, patterns and policies. Intereconomics, 49, 116-158.

Berg, L., \& Hjerm, M., (2010). National Identity and Political Trust. Perspectives on European Politics and Society, 11, 390-407.

Bilgen-Susanli, Z., Inanc-Tuncer. O., \& Kologlugil, S. (2016). Child domestic labour and mothers' employment in Turkey. Economic Research-Ekonomska Istraživanja, 29(1), 967-979, DOI: 10.1080/1331677X.2016.1204100

Bobáková V. (2017). The formation of regional self-government in the Slovak Republic and its sources of funding. Administratie si Management Public, (28), 97-115.

Boomgaarden, H.G., \& Freire, A., (2009). Religion and Euroscepticism: Direct, Indirect or No Effects? West European Politics, 32, 1240-1265.

Borjas, G.J., (2003). The Labor Demand Curve Is Downward Sloping: Reexamining the Impact of Immigration on the Labor Market. Quarterly Journal of Economics, 118, 1335-1374.

Ceobanu, A.M., \& Escandell, X., (2010). Comparative Analyses of Public Attitudes toward Immigrants and Immigration Using Multinational Survey Data: A Review of Theories and Research. Annual Review of Sociology, 36, 309-328.

Dustmann, C., Glitz, A., \& Frattini, T., (2008). The labour market impact of immigration. Oxf Rev Econ Policy, 24, 477-494.

Florack, A., Piontkowski, U., Rohmann, A., Balzer, T., \& Perzig, S. (2003). Perceived intergroup threat and attitudes of host community members toward immigrant acculturation. The Journal of social psychology, 143(5), 633-648. 
Fukuyama, F. (1995). Trust: The social virtues and the creation of prosperity. Free Press Paperbacks.

Green, D.P., \& Seher, R.L. (2003). What Role Does Prejudice Play in Ethnic Conflict? Annual Review of Political Science, 6, 509-531.

Green, E.G.T. (2007). Guarding the gates of Europe: A typological analysis of immigration attitudes across 21 countries. International Journal of Psychology, 42, 365-379.

Hardin, R. (2002). Trust and Trustworthiness, Russell Sage Foundation, New York.

Healy, A.E., \& Breen, M. (2014). Religiosity in times of insecurity: an analysis of Irish, Spanish and Portuguese European Social Survey data, 2002-12. Irish Journal of Sociology, 22, 4 29.

Holicza P., \& Stone A.M. (2016). Beyond The Headlines: Economic Realities of Migration and the Labour Market in Malta, Journal of International Studies, 9(3), 88-98. DOI: 10.14254/2071-8330.2016/9-3/7

Hooghe, M., Reeskens, T., Stolle, D., \& Trappers, A. (2006). Ethnic Diversity, Trust and Ethnocentrism and Europe. A Multilevel Analysis of 21 European Countries. Conference Papers - American Political Science Association, 1-26.

Huysmans, J. (2000). The European Union and the Securitization of Migration. JCMS: Journal of Common Market Studies, 38, 751-777.

Ivarsflaten, E. (2005). Threatened by diversity: Why restrictive asylum and immigration policies appeal to western Europeans. Journal of Elections, Public Opinion \& Parties, 15, $21-45$.

Jantoń-Drozdowska, E., \& Majewska, M. (2015). Social capital as a key driver of productivity growth of the economy: across-countries comparison, Equilibrium. Quarterly Journal of Economics and Economic Policy, 10(4), 61-83.

Jędrzejowska-Schiffauer, I., \& Schiffauer, P. (2017). New constraints on mobility in Europe: Policy response to European crises or constitutional ambiguity?. Journal of International Studies, 10(3), 9-23. doi:10.14254/2071-8330.2017/10-3/1

Jepperson, R.L. (1991). Institutions, Institutional Effects, and Institutionalism. In: Powell, W.W., DiMaggio, P.J. (Eds.). The New Institutionalism in Organizational Analysis. University of Chicago Press, pp. 143-163.

Karyotis, G., \& Patrikios, S. (2010). Religion, securitization and anti-immigration attitudes: The case of Greece. Journal of Peace Research, 47(1), 43-57.

Kotulič, R., \& Adamišin, P. (2012). Migration trends of the labor force in the Slovak republic at the beginning of the second millennium. Polish Journal of Management Studies, 6, 8188 .

Lobonţ, O.R., Nicolescu, A.C., Moldovan, N.C. \& Kuloğlu, A. (2017). The effect of socioeconomic factors on crime rates in Romania: a macro-level analysis, Economic Research-Ekonomska Istraživanja, 30(1), 91-111. doi:10.1080/1331677X.2017.1305790

Loader, I., \& Mulcahy, A. (2003). Policing and the Condition of England: Memory, Politics and Culture. Oxford University Press.

Mačerinskienè, I., \& Aleknavičiūtè, R. (2017). National intellectual capital influence on economic growth in the European Union countries. Equilibrium. Quarterly Journal of Economics and Economic Policy, 12(4), 573-592.

Madrak-Grochowska, M. (2015). The knowledge-based economy as a stage in the development of the economy. Oeconomia Copernicana, 6(2), 7-21.

Martin, P.L. (1994). Comparative Migration Policies. The International Migration Review, 28, 164-170.

Meuleman, B., Davidov, E., \& Billiet, J. (2009). Changing attitudes toward immigration in Europe, 2002-2007: A dynamic group conflict theory approach. Social Science Research $38,352-365$. 
Mikalauskiene, A., Streimikiene, D., \& Mazutaityte-Cepanoniene, E. (2017). Employers' Openness to Labour Immigrants. Economics and Sociology, 10(3), 25-45. doi:10.14254/2071-789X.2017/10-3/2

Newton, K. (2001). Trust, Social Capital, Civil Society and Democracy. International Political Science Review, 22, 201-14.

Newton, K., \& Zmerli, S. (2011). Three forms of trust and their association, European Political Science Review, 3(2), 169-200.

Pan Ké Shon, J.-L., Verdugo, G., 2015. Forty years of immigrant segregation in France, 19682007. How different is the new immigration?. Urban Studies, 52, 823-840.

Petersons, A., \& Khalimzoda, I. (2016). Communication privacy management of students in Latvia. Problems and Perspectives in Management, 14(2-1), 222-227. doi:10.21511/ppm.14(2-1).2016.11

Rollnik-Sadowska, E., \& Dąbrowska, E. (2018). Cluster analysis of effectiveness of labour market policy in the European Union, Oeconomia Copernicana, 9(1), 143-158.

Rustenbach, E. (2010). Sources of Negative Attitudes toward Immigrants in Europe: A MultiLevel Analysis1. International Migration Review, 44, 53-77.

Samuel, H., (2014). Hollande warns of "discourse of fear" on immigration. The Telegraph.

Simon, R.J., \& Sikich, K.W., (2007). Public Attitudes toward Immigrants and Immigration Polices across Seven Nations. The International Migration Review, 41, 956-962.

Strielkowski, W., \& Weyskrabova, B. (2014). Ukrainian Labour Migration and Remittances in the Czech Republic. Tijdschrift voor economische en sociale geografie, 105(1), 30-45. https://doi.org/10.1111/tesg.12052

Solomon, R., \& Flores, F. (2001). Building Trust in Business, Politics, Relationships, and Life. New York: Oxford University Press.

Uslaner, R. (2008). The foundations of trust: macro and micro. Cambridge Journal of Economics, 32, 289-94.

Tvaronavičienè, M. (2018). Preconditions of sustainable entrepreneurship: Estimating of Brexit scenarious impact on macroeconomic environment. Polish Journal of Management Studies, 17(2), 222-234.

Vasile, O., \& Androniceanu, A. (2018). An overview of the Romanian Asylum Policies. Sustainability, 10(5), May, Article number: 1461. doi:10.3390/su10051461 